\title{
Alteraciones conductuales por la enfermedad por coronavirus
} 2019

\section{Behavioral alterations due to coronavirus disease 2019}

\section{Liliana R. Carlos-Gutiérrez* y Rogher H. Trejo-Rodríguez}

Escuela Profesional de Medicina Humana, Universidad Privada San Juan Bautista, Filial Chorrillos, Lima, Perú

\section{Estimado Editor,}

Con mucho interés hemos leído la investigación de Galindo, et al., en la cual se realizó un estudio mediante una encuesta en línea en la población general, para determinar alteraciones conductuales por la enfermedad por coronavirus 2019 (COVID- 2019). Por ello consideramos relevante proponer tres medidas de apoyo terapéutico en diferentes poblaciones:

- Línea CONVIDA: se trata de una línea móvil de ayuda psicológica que permitió una marcada disminución, del 60\%, de los síntomas de ansiedad y depresión en la población de Cuba; por ende, podría ser de mucha utilidad implementarla en Perú1.

- Técnicas cognitivo-conductuales: basadas principalmente en la "detención del pensamiento» para evitar ideas negativas que lo único que ocasionan es mucho daño a nivel emocional ${ }^{2}$.
- Redes sociales: páginas de información actualizada vía redes sociales sobre medidas preventivas específicamente ante problemas de ansiedad y depresión, con el fin de ayudar a afrontar la COVID-2019 de una forma más realista².

En conclusión, es vital la orientación psicológica por profesionales debidamente capacitados para poder ayudar con el tratamiento sobre el desequilibrio emocional causado por la COVID-2019 en diversas poblaciones.

\section{Bibliografía}

1. Valladares González AM, López Angulo LM, Valladares González AM, López Angulo LM. Línea CONVIDA. Propuesta de guía práctica psicológica ante la situación emergente de la COVID 19. Cienfuegos, 2020. MediSur. 2020;18(3):416-30.

2. Huarcaya-Victoria J. Consideraciones sobre la salud mental en la pandemia de COVID-19. Rev Peru Med Exp Salud Publica. 2020; $37(2): 327-34$
Gac Med Mex. 2021:157:573

Disponible en PubMed www.gacetamedicademexico.com CC BY-NC-ND (http://creativecommons.org/licenses/by-nc-nd/4.0/). 